\title{
Análise das práticas de Gestão Ambiental das Instituições de Ensino Superior
}

\author{
Analysis of environmental management practices of Higher Education Institutions \\ Kamila Frizzo', Francies Diego Motke², Emanuelly Comoretto Machado3, \\ Ygor Cezar Silva ${ }^{4}$, Lucas Veiga Ávila ${ }^{5}$, João Fernando Zamberlam ${ }^{6}$ \\ 1, 2, 3, 4, 5, 6 Universidade Federal de Santa Maria, Santa Maria, RS, Brasil
}

\section{Resumo}

A gestão ambiental tornou-se um tema emergente que vem ganhando espaço crescente no meio acadêmico e empresarial, a qual as organizações devem não estar somente preocupadas em atender normas e leis, mas, também, está procurando atender melhor seus clientes que se tornam cada vez mais exigentes, envolvendo diferentes camadas e setores da sociedade, em especial o setor da educação, como as Instituições de Ensino Superior (IES) que são formadoras de profissionais e possuem representatividade na sociedade. Portanto, o presente estudo objetiva identificar as práticas de gestão ambiental adotadas pelas Instituições de Ensino Superior (IES) presenciais na cidade de Santa Maria/ RS. A pesquisa caracteriza-se como exploratória e adotou como método o estudo de multicasos. Os principais resultados revelaram que as práticas de gestão ambiental adotadas pelas instituições analisadas são incipientes e caracterizam-se como isoladas por serem implementadas apenas em alguns setores da Instituição. Os resultados expressam, falta de consciência e planejamento dos gestores, carência de um setor específico de gestão ambiental, falta de relatórios, espaços verdes para conscientização dos discentes, docentes e colaboradores. Uma vez que as instituições participantes não possuem nenhum padrão de certificação ambiental.

Palavras-chave: Educação ambiental; Sustentabilidade; Instituições de Ensino Superior.

\begin{abstract}
Environmental management has become an emerging issue that has been increasingly growing in academia and business, which organizations should not only be concerned with meeting standards and laws, but also are seeking to better serve their customers become increasingly more demanding, involving different layers and sectors of society, especially the education sector, such as the Higher Education Institutions (HEI) that are forming professional and have representation in society. Therefore, this study aims to identify the environmental management practices adopted by Higher Education Institutions (HEI) face in the city of Santa Maria / RS. The research is characterized as exploratory and adopted as a method to study multi cases. The main results revealed that environmental management practices adopted by the institutions analyzed are incipient and characterized as isolated as they are implemented only in some sectors of the institution. The results show, lack of awareness and planning managers, lack of a specific industry environmental management, lack of reporting, awareness of green spaces for students, faculty and staff. Once the participating institutions have no environmental certification standard.
\end{abstract}

Keywords: Environmental Education, Sustainability, Higher Education Institutions. 


\section{INTRODUÇÃO}

O desenvolvimento tecnológico e econômico gerou reflexos na sociedade e no meio ambiente, causando numerosos problemas, tais como: aquecimento global, desmatamento, problemas de saneamento básico, qualidade do ar, geração demasiada de resíduos, entre outros que comprometem e ameaçam a vida terrestre.

A crise socioambiental ocorrida em meados da década de 1960 serviu como base para a emergência da temática alusiva ao Desenvolvido Sustentável. Na Assembleia Geral da ONU em 1983, foi criada a Comissão Mundial para o Meio Ambiente e Desenvolvimento (CMMAD), na qual foi elaborado o Relatório Brundtland em 1987, que estabelece o compromisso dos governos signatários com a preservação do meio ambiente, definindo o conceito de DS como o "desenvolvimento capaz de suprir as necessidades da geração atual, sem comprometer a capacidade de atender as necessidades das futuras gerações" (CMMAD, 1991, p.9).

O surgimento da ideia de DS marca a emergência de uma nova maneira de se pensar no desenvolvimento, sem restrição unicamente da esfera econômica, mas também considerando aspectos sociais e ambientais.

A gestão ambiental vem ganhando espaço no meio empresarial, onde as empresas devem se adequar a rigorosas legislações e, mais do que isso, satisfazer consumidores cada vez mais preocupados com a utilização consciente dos recursos naturais. Esta consciência ecológica acaba também por envolver o setor da educação, a exemplo das Instituições de Ensino Superior (IES). Porém, ainda são poucas as práticas adotadas pelas IES, que tem papel fundamental de qualificar e conscientizar os cidadãos formadores de opinião.

Segundo Mayor (1998) a educação é a chave do desenvolvimento sustentável e auto-suficiente, e deve ser fornecida a todos os membros da sociedade, de tal maneira que cada um se beneficie de chances reais de se instruir ao longo da vida.

Diante do exposto, definiu-se como principal objetivo do estudo, identificar as práticas de gestão ambiental adotadas pelas Instituições de Ensino Superior (IES) presenciais da cidade de Santa Maria/RS.

\section{REFERENCIAL TEÓRICO}

Este segmento tem como objetivo apresentar o referencial teórico que serviu de suporte para o presente trabalho, ou seja: conceitos de Desenvolvimento Sustentável e Sustentabilidade e Gestão Ambiental nas Instituições de Ensino Superior

\section{I DesenVolVIMENTO SUSTENTÁVEL E SUSTENTABiLIDADE}

Meio ambiente é o local onde vivemos, onde estamos inseridos e que para mantermos um bom padrão de vida utilizamos de seus recursos naturais disponíveis de forma irracional e irrestrita o que tem contribuído para sua depleção sem que sejam respeitados os seus limites de resiliência. Segundo Dias (2011), a partir do século XVIII o crescimento econômico desordenado foi acompanhado de um processo industrial em que se utilizavam grandes quantidades de energia e de recursos naturais, que acabaram por configurar um quadro de degradação contínua do meio ambiente. Tal industrialização trouxe vários problemas ambientais, como: alta concentração populacional, devido à urbanização acelerada; consumo excessivo de recursos naturais, sendo que alguns não renováveis (petróleo e carvão mineral, por exemplo); contaminação do ar, do solo, das águas; e desflorestamento.

$\mathrm{Na}$ metade do século XX, com a intensificação do crescimento econômico mundial, os problemas ambientais se agravaram e começaram a aparecer com maior visibilidade. Isso foi observado até o ano de 1962, onde os problemas derivados da relação do homem com o meio ambiente foram abordados de forma muito superficial.

Portanto, no início da década de 1990, o meio ambiente ocupou um patamar privilegiado na agenda global, tendo se tornado um assunto quase obrigatório nos inúmeros encontros internacionais. Caracterizando-se por um período de intensos debates, atividades, fóruns e encontros que resultaram em um consenso mundial dos perigos que o planeta corria, caso se mantivesse o modelo de crescimento insustentável até então em vigor (DIAS, 2011).

Em 1987, a Comissão Mundial sobre Meio Ambiente e Desenvolvimento (CMMAD) difun- 
diu o relatório Nosso Futuro Comum, também chamado relatório de Brundtland, onde foi exposto o primeiro conceito de DS. Essa comissão analisou a viabilidade de prover necessidades mínimas para o dobro da população mundial, de maneira sustentável e sem deterioração dos ecossistemas globais, com o objetivo de atender às necessidades da geração presente sem comprometer a habilidade das gerações futuras de atender suas próprias necessidades (AMARAL e ROVERE, 2003).

Desde 1972, o conceito de sustentabilidade vem sendo analisado com a concretização da Conferência de Estocolmo, que abordou especificamente dos problemas com a poluição ambiental. A mesma foi o ponto inicial para que, nos anos seguintes, muitos outros movimentos se voltassem para a problemática da conservação dos recursos naturais. No Brasil, três conferências ganharam destaque: a Conferência Rio-92, de 1992, a Conferência Rio+5, de 1997 e RIO + 20 em 2012. Sendo que a primeira foi responsável pela introdução do conceito de Desenvolvimento Sustentável e a Rio+5 uma consequente avaliação de resultados da Conferência Rio-92 (BRASIL, 1998; RIBEIRO; PROFETA, 2004; FARIAS; TEIXEIRA, 2006).

Para Sachs (1993), o desenvolvimento sustentável só será adquirido se três critérios forem obedecidos concomitantemente: equidade social, preservação ambiental e eficiência econômica. Elkington (1998), fundamentado nesses critérios, desenvolveu o conceito do Triple Bottom Line:

- Na perspectiva econômica tem-se a preservação da lucratividade da organização e o não comprometimento do seu desenvolvimento econômico;

- A esfera social inclui a questão da justiça social, onde a maior finalidade é o desenvolvimento de um mundo mais justo, por meio das relações com todos os stakeholders (colaboradores, clientes, fornecedores, governo);

E na esfera ambiental destaca-se a utilização dos recursos de modo a não prejudicar as gerações futuras, com isso diminuindo impactos da ação das indústrias e utilizando de maneira sustentável os recursos naturais.

Barbieri (2007) afirma que os problemas gerados pelos humanos decorrem do uso inadequado do meio ambiente para obter os recursos necessários para produzir bens e serviços e do despejo de materiais e energia não aproveitados no meio ambiente. Um conceito consistente de gestão ambiental é aquele que a entende como sendo uma estrutura gerencial que permite que a organização visualize os impactos de suas ações no meio ambiente (SILVA, SILVA e ENDERS, 2006).

Está cada vez mais evidente que toda iniciativa de negócio tem um impacto sobre o lucro e sobre o mundo. Dessa forma, o desempenho social inadequado e a falta de políticas bem elaboradas de cunho social e ambiental podem ter sérias implicações organizacionais, acarretando prejuízos materiais e morais de modo a aumentar os custos e perder oportunidades de mercado. Não há como ignorar o novo compromisso das empresas, pois a questão não é parte apenas de uma sensibilização ética, mas principalmente, econômica e mercadológica. (ALIGLERI, ALIGLERI e KRUGLIANSKAS, 2009).

Destaca-se a existência de uma norma internacional quanto ao gerenciamento ambiental, à norma ISO 14001, elaborada pela International Organization for Standardization (ISO), fundada no ano de 1947, localizada em Genebra, na Suíça. Ressalta-se que a ISO é considerada como uma norma de gerenciamento e não como uma norma de desempenho ou de produto. Seu objetivo é focalizar o processo de gerenciamento das atividades da organização que afetam diretamente o ambiente (NASCIMENTO; LEMOS; MELLO, 2008). Logo, os requisitos da norma são fundamentados nos seguintes aspectos: exigências gerais; política ambiental; planejamento; execução e operação; verificação e ação corretiva; e revisão da administração (ABNT, 2004). Com isso, torna-se importante a prática de gestão ambiental também para as Instituições de Ensino Superior.

\subsection{GESTÃO AMBIENTAL NAS INSTITUIÇÕES DE ENSINO SUPERIOR}

A partir da década de 1960, as IES passaram a introduzir o tema ambiental na sua gestão. As primeiras experiências surgiram nos Estados Unidos, concomitantemente com as promoções de profissionais nas ciências ambientais, que se estenderam ao longo dos anos setenta. Já nos anos de 1980, o destaque foi para políticas específicas à gestão de resíduos e eficiência energética. Durante a década de noventa se desenvolveram políticas ambientais de domínio global, que agrupam todos os âmbitos das instituições (DELGADO e VÉLEZ, 2005).

Ainda que o assunto tenha gerado grande repercussão nos últimos anos, são poucas as políticas de ensino superior voltadas para as práticas de gestão ambiental. Jacobi (2003) acredita que seja necessário criar condições necessárias para facilitar o processo de educação ambiental, suprindo 
dados, desenvolvendo e difundindo indicadores com o objetivo de tornar claros os procedimentos que garantam os meios de criar estilos de vida e promovam uma consciência ética que questione o atual modelo de desenvolvimento.

Deste modo, seria desejável o estabelecimento de uma política universitária referente à questão ambiental, objetivando a criação de estratégias que não só interfiram na organização acadêmica e nos currículos, mas também colabore para mudanças diárias nas relações ensino aprendizagem, nas relações com a sociedade, nas pesquisas e acima de tudo nos valores individuais e dos grupos, fazendo-os receptivos e dispostos ao trabalho interdisciplinar, interativo, crítico, holístico, voltado à solução de problemas (SORRENTINO apud GUIMARÃES; TOMAZELLO,2011).

Segundo Careto e Vendeirinho (2003) as Universidades e outras Instituições de Ensino Superior em outros níveis precisam praticar aquilo que ensinam. As universidades são muitas vezes vistas como instituições estagnadas e burocráticas, por outro percebe-se como organizações capazes de iniciar o caminho da sustentabilidade.

Barbieri (2004) destaca que na maior parte dos programas dos cursos superiores, a Educação Ambiental não passa de atividade isolada realizada somente no dia do meio ambiente ou de programas de coleta seletiva de lixo, originados nas dependências da instituição. Observa-se que as Universidades se confrontam com alterações profundas nas condições de produzir conhecimento e provocar a mudança (A. COUTO et al, 2004)

$\mathrm{Na}$ visão de Weenem (2000) há várias formas das Universidades promoverem o DS, seja por meio de ações de planejamento, gestão, desenvolvimento, ensino, pesquisa, operações, extensão, compras, transporte, construções, dentre outros. Desse modo, diversas práticas de Gestão Ambiental foram identificadas a partir das normas de implementação para Sistemas de Gestão Ambiental da NBR ISO 14001 (ISO, 1996), e por pesquisas realizadas por Careto e Vendeirinho (2003), Tauchen e Brandli (2006) e Engelman, Guisso e Fracasso (2009):

- Políticas de Gestão Ambiental;

- Guia de boas práticas de ações ambientais/ sustentáveis;

- Auditoria ambiental para indicar melhorias;

- Utilização de indicadores ambientais;

- Acompanhamento e análise da questão de sustentabilidade ambiental;

- Diagnóstico dos impactos significativos para o ambiente;

- Soluções baseadas no padrão ISO 14001;

- Departamento/área para Gestão Ambiental;

- Construções e reformas na instituição seguindo padrões de sustentabilidade;

- Cursos de formação de gestores ambientais;

- Treinamento e sensibilização da equipe de funcionários;

- Programas de conscientização ambiental voltado à população;

- Programas de conscientização ambiental voltado aos alunos;

- Inclusão no currículo de conteúdos sobre sustentabilidade ambiental;

- Desenvolvimento de projetos de pesquisa sobre sustentabilidade ambiental;

- Disseminação dos projetos ambientais desenvolvidos dentro da instituição;

- Parceria com outras Universidades para desenvolver a questão ambiental;

- Organização de eventos sobre a questão ambiental;

- Disponibilização de alimentação orgânica;

- Controle de consumo e reuso de água;

- Controle de consumo de energia;

- Controle de efluentes;

- Controle de resíduos;

- Racionalização do uso de combustíveis;

- Uso de combustíveis alternativos;

- Utilização de material reciclado (papel);

- Programas de seleção do lixo;

- Critérios ambientais para fornecedores de materiais de consumo;

- $\quad$ Espaços verdes - controle da vegetação;

- Plano de ação para melhoria contínua da sustentabilidade ambiental. 


\section{MÉTODO}

O referido capítulo aborda os procedimentos metodológicos utilizados a fim de atingir o objetivo proposto e confirmar ou não o pressuposto. A seguir são descritos os principais procedimentos utilizados nesta pesquisa e o pressuposto que direciona o estudo.

P1: As Instituições de Ensino Superior (IES) presenciais de Santa Maria/RS adotam práticas de gestão ambiental.

Esta pesquisa caracteriza-se por ser uma investigação de natureza exploratória, de abordagem qualitativa, que tem como finalidade identificar o comportamento das IES presenciais de Santa Maria, visando a conhecer as principais práticas de gestão ambiental desenvolvidas pelas mesmas. Conforme Gil (2007), a pesquisa exploratória tem por finalidade ampliar o conhecimento a respeito de determinado fenômeno, explorando uma determinada realidade.

Para a consecução dos objetivos da pesquisa será utilizado o estudo de casos múltiplos. $\mathrm{O}$ método do estudo de caso é definido por Yin (1990) como uma estratégica de pesquisa que visa estudar fenômenos sociais complexos, a qual possibilita reter características holísticas e significativas dos eventos no seu contexto real. Para Yin (2011), no tipo de pesquisa de caso múltiplo, uma das vantagens é que ele se torna mais convincente, além de ser um estudo global, mais robusto. Eisenhardt (1989) contempla que o estudo de caso se fixa no entendimento da situação presente dinâmica, dentro de um conjunto específico e particular.

Os dados foram coletados por meio de entrevistas semiestruturadas aos responsáveis pelo setor ambiental nas Instituições de Ensino Superior Presenciais de Santa Maria, que foram gravadas e, após, transcritas. A coleta de dados ocorreu no mês de julho de 2013 em três instituições de ensino superior presenciais na cidade de Santa Maria/RS selecionadas pelo critério de acessibilidade. Visando a preservação da sua identidade, as instituições analisadas foram denominadas: INST1, INST2 e INST3.

O protocolo de entrevista foi elaborado com base nas normas de implementação para Sistemas de Gestão Ambiental da NBR ISO 14001 (ISO, 1996), e por pesquisas realizadas por Careto e Vendeirinho (2003), Tauchen e Brandli (2006) e Engelman, Guisso e Fracasso (2009).

\subsection{ANÁLISE DOS DADOS}

A partir das entrevistas, os dados foram analisados por meio de análise de conteúdo, que segundo Moraes (1999) consiste em uma técnica para leitura e interpretação do conteúdo de materiais oriundo de comunicação verbal ou não verbal. Para o autor, a análise de conteúdo, de certa forma não deixa de ser uma interpretação pessoal por parte do pesquisador com relação à percepção que tem dos dados analisados. A estrutura de apresentação das evidências foi organizada em três categorias de análise: estrutura física, legislação e normativas e gestão ambiental.

Quadro 1 - Categorias de análise e os aspectos analisados

\begin{tabular}{|c|c|}
\hline Categorias & \multicolumn{1}{|c|}{ Aspectos analisados } \\
\hline & $\begin{array}{l}\text { Construções e reformas seguindo padrões } \\
\text { sustentáveis; }\end{array}$ \\
Estrutura Física & $\begin{array}{l}\text { Promove a biodiversidade dos ecossistemas do } \\
\text { campus; }\end{array}$ \\
& $\begin{array}{c}\text { Apresenta espaços verdes e realiza controle da } \\
\text { vegetação. }\end{array}$ \\
\hline
\end{tabular}


Quadro 1 - Continuação

\begin{tabular}{|c|c|}
\hline Categorias & Aspectos analisados \\
\hline $\begin{array}{l}\text { Legislação e } \\
\text { Normativas }\end{array}$ & $\begin{array}{l}\text { - Padrão de certificação ambiental; } \\
\text { - Avaliação para reconhecimento e renovação do } \\
\text { reconhecimento dos cursos de graduação no que } \\
\text { se refere à Educação Ambiental. }\end{array}$ \\
\hline Gestão Ambiental & $\begin{array}{l}\text { - Manual com boas práticas sustentáveis; } \\
\text { - Auditoria ambiental; } \\
\text { - Diagnóstico dos impactos significativos para o } \\
\text { ambiente; } \\
\text { - Treinamento e sensibilização dos funcionários; } \\
\text { - Treinamento e sensibilização dos alunos ; } \\
\text { - Sustentabilidade ambiental nos currículos; } \\
\text { - Controle do uso da energia/eficiência energética; } \\
\text { - Programa de reciclagem e/ou gestão de resíduos; } \\
\text { - Analisa critérios de gestão ambiental dos seus } \\
\text { fornecedores de materiais de consumo. }\end{array}$ \\
\hline
\end{tabular}

\section{RESULTADOS E DISCUSSÕES}

A partir das entrevistas realizadas são apresentadas as principais características que definem o perfil das instituições participantes da pesquisa e dos responsáveis pelas informações obtidas, através da qual foi possível identificar a percepção e a compreensão das ações focadas no desenvolvimento sustentável através de sua experiência na organização.

Por conseguinte, os resultados analisados foram sumarizados na seguinte categoria de análise: estrutura física, legislação normativa e gestão ambiental.

\section{I CARACTERIZAÇÃo das InSTITUIÇões}

A INST 1, criada em 1960, é pública e oferece 317 cursos distribuídos em cinco polos com graduação presencial, graduação à distância e pós-graduação. Possui 28.323 estudantes, 1.821 professores e 2.782 técnicos administrativos em educação. O responsável pelas informações é professor associado da instituição e coordenador da comissão ambiental, que atua há trinta anos como professor e há onze anos na comissão ambiental.

A INST 2, criada em 2004, é particular e oferece um curso de graduação presencial. Possui, em média, seiscentos e cinquenta estudantes, quarenta e cinco professores e cerca de cinquenta funcionários. O responsável pelas informações é coordenador de comunicação, atuando nesta área há quase cinco anos.

A INST 3, criada em 2000, é particular e oferece quatro cursos presenciais de graduação e quatro cursos de pós-graduação. Possui, em média, quinhentos estudantes, sessenta professores e quinze funcionários. O responsável pelas informações é coordenador acadêmico e atua na instituição há três anos. 


\subsection{Estrutura Física}

Em relação a estrutura física das instituições, é apresentada no Quadro 2 uma síntese das suas principais evidências.

Quadro 2 - Evidências no que se refere à estrutura física

\begin{tabular}{|c|c|}
\hline \multicolumn{2}{|c|}{ Estrutura Física } \\
\hline Principais práticas & Evidências \\
\hline $\begin{array}{l}\text { Construções e reformas seguindo } \\
\text { padrões sustentáveis }\end{array}$ & $\begin{array}{l}\text { INST 1: "Há iniciativas neste sentido, } \\
\text { mas por enquanto ela fica no contexto } \\
\text { da equipe de arquitetura que elabora os } \\
\text { projetos que recebeu treinamento neste } \\
\text { sentido". } \\
\text { INST 2: "Não, mas não deixa de ser uma } \\
\text { pretensão". } \\
\text { INST 3: "Foi feito toda a climatização do } \\
\text { prédio com a preocupação com o meio } \\
\text { ambiente". }\end{array}$ \\
\hline $\begin{array}{l}\text { Promove a biodiversidade dos } \\
\text { ecossistemas do campus }\end{array}$ & $\begin{array}{l}\text { INST 1: “... hoje observa-se bastante } \\
\text { plantação, mas toda ela foi plantada". } \\
\text { INST 2: "Não tem área verde". } \\
\text { INST 3: “... aqui dentro a gente não tem } \\
\text { esse espaço". }\end{array}$ \\
\hline $\begin{array}{l}\text { Apresenta espaços verdes e realiza } \\
\text { controle da vegetação }\end{array}$ & $\begin{array}{l}\text { INST 1: "Tem vários espaços verdes mas } \\
\text { são todos artificiais. O pouco que existe } \\
\text { ainda é remanescente do bioma pampa e } \\
\text { a tendência é serem modificados". } \\
\text { INST 2: "Não". } \\
\text { INST 3: "aqui dentro a gente não tem } \\
\text { esse espaço". }\end{array}$ \\
\hline
\end{tabular}

No caso da estrutura física das instituições, evidenciou-se que todas as instituições analisadas demonstram-se preocupadas em seguir padrões sustentáveis em suas construções e reformas de modo a reduzir as agressões ao meio ambiente. A INST1, porém, afirmou que esta vontade ainda não se configura em resultados práticos, porque normalmente a verba liberada pelos órgãos responsáveis para os projetos é muito limitada e não possibilita que haja a implementação de projetos sustentáveis, corroborando com Placet, Anderson e Fowler (2005), que a implementação da sustentabilidade como estratégia é um desafio, pois para muitas organizações a estratégia é uma ferramenta utilizada apenas para diminuir custos e expandir os negócios, enquanto a proteção ambiental é vista como desnecessária e cara.

Observou-se, ainda, que apenas a INST1 possui espaços verdes, porém, foi denominado como artificial pelo fato de toda vegetação existente ter sido plantada, restando pouco do bioma original. Já as demais instituições alegam não possuir espaços destinados à vegetação. 


\subsection{Legislação e Normativas} Quadro 3

As principais evidências observadas, em relação a legislação e normativas, são destacadas no

Quadro 3 - Evidências no que se refere à legislação e as normativas.

\begin{tabular}{|c|c|}
\hline \multicolumn{2}{|c|}{ Legislação e Normativas } \\
\hline Principais práticas & Evidências \\
\hline $\begin{array}{l}\text { Baseia-se algum padrão de } \\
\text { certificação ambiental }\end{array}$ & $\begin{array}{l}\text { INST 1: "No momento não tem nenhum tipo } \\
\text { de certificação"; "A ISO vem a ser uma meta } \\
\text { futura". } \\
\text { INST 2: "Não". } \\
\text { INST 3: “... isso eu não saberia te dizer". }\end{array}$ \\
\hline $\begin{array}{l}\text { Atende ao requisito legal da } \\
\text { avaliação para reconhecimento e } \\
\text { renovação do reconhecimento dos } \\
\text { cursos de graduação no que se refere } \\
\text { à Educação Ambiental (Lei no } 9.795 \text { e } \\
\text { Decreto № } 4.281 \text { ) }\end{array}$ & $\begin{array}{l}\text { INST 1: "Nós não temos curso de graduação } \\
\text { de educação ambiental. O que existe são } \\
\text { diversos cursos em várias áreas". } \\
\text { INST 2: "Nós não temos o curso de educação } \\
\text { ambiental, hoje o direito ambiental é uma das } \\
\text { áreas mais promissoras". } \\
\text { INST 3: "Todos os cursos tem essa disciplina } \\
\text { obrigatória no currículo. }\end{array}$ \\
\hline
\end{tabular}

Quanto à legislação, observou-se que a INST1 e a INST2 não possuem nenhum padrão de certificação ambiental, sendo que a INST1 afirma ser uma meta futura da organização, e a INST3 não soube responder. Quanto ao requisito legal da avaliação dos cursos de graduação no que se refere à educação ambiental, os respondentes informaram que não possuem curso específico de Gestão Ambiental, sendo apenas trabalhada em outros cursos, e na INST3 a disciplina é obrigatória.

\subsection{Gestão AmbientAL}

A síntese das principais evidências encontradas a partir das práticas de gestão ambiental é apresentada no Quadro 4.

As instituições analisadas informaram não possuir um guia e/ou manual com boas práticas sustentáveis que oriente toda a instituição, porém, a INST1 afirmou que está em processo de elaboração e que, no momento possui este tipo de material em alguns setores. Já a INST3, apesar de não elaborar um guia ou manual, alega ter uma equipe responsável pela conscientização e orientação.

No que se refere a realização de auditora ambiental para propor melhorias necessárias, a INST1 afirmou não realizá-la por possuir problemas estruturais e, a INST2, pelo fato de suas ações não serem formais a ponto de se caracterizar como uma auditoria. Já a INST3, por estar inserida em um complexo formado por outras organizações, consequentemente, participa das auditorias realizadas.

Para a avaliação dos impactos diretos ou significativos para o ambiente, a INST1 informou já ter realizado este diagnóstico e que estão otimizando a destinação correta de todos os impactos. No caso da INST2, o diagnóstico não é formalizado e na INST3 o responsável pelas informações cita que os impactos não são significativos devido ao tamanho da instituição.

Quanto ao treinamento e sensibilização dos alunos e funcionários em relação a sustentabilidade, as três instituições demonstram preocupação em inserir seus colaboradores no contexto ambiental. Apesar disto, a INST1 esclarece que os cursos de atualização para os colaboradores são oferecidos através da pró-reitoria de recursos humanos, contudo não está interligada com as ações da comissão 
Quadro 4 - Evidências no que se refere à gestão ambiental

\begin{tabular}{|c|c|}
\hline \multicolumn{2}{|r|}{ Gestão Ambiental } \\
\hline Principais práticas & Evidências \\
\hline $\begin{array}{l}\text { Guia e/ou manual com boas } \\
\text { práticas sustentáveis }\end{array}$ & $\begin{array}{l}\text { INST 1: “Está sendo elaborado um documento reunindo } \\
\text { tudo isso. Existem setorizados". } \\
\text { INST 2: “... não tem nada formalizado ...” } \\
\text { INST 3: “...tem uma equipe que trabalha com isso e faz } \\
\text { esses regimentos internos, esse trabalho de conscientização } \\
\text { e orientação". }\end{array}$ \\
\hline $\begin{array}{l}\text { Auditoria ambiental para } \\
\text { propor melhorias necessárias }\end{array}$ & $\begin{array}{l}\text { INST 1: "Ela não faz auditoria, porque há uma série de } \\
\text { problemas estruturais a serem resolvidos antes". } \\
\text { INST 2: "As ações que possui não são formais a ponto de } \\
\text { serem consideradas auditorias". } \\
\text { INST 3: "dentro desse complexo... a faculdade entra junto } \\
\text { dessas auditorias..." }\end{array}$ \\
\hline $\begin{array}{l}\text { Diagnóstico dos impactos } \\
\text { diretos ou significativos para o } \\
\text { ambiente }\end{array}$ & $\begin{array}{l}\text { INST 1: “Esses levantamentos já foram feitos e hoje nós } \\
\text { estamos otimizando a destinação correta de todos”. } \\
\text { INST 2: “... não tem nada formalizado nesse momento”. } \\
\text { INST 3: “... por ser uma instituição pequena eles não são } \\
\text { tão representativos". }\end{array}$ \\
\hline $\begin{array}{l}\text { Treinamento e sensibilização } \\
\text { dos funcionários em relação à } \\
\text { sustentabilidade }\end{array}$ & $\begin{array}{l}\text { INST 1: "São oferecidos cursos de atualização dos } \\
\text { funcionários através da pró-reitoria de recursos humanos, } \\
\text { mas ela não está interligada, isso faz parte de um } \\
\text { planejamento...". } \\
\text { INST 2: "os funcionários recebem periodicamente oficinas, } \\
\text { palestras, seminários que façam com que eles tenham uma } \\
\text { progressão, aprimoramento não só profissional, como } \\
\text { pessoal". } \\
\text { INST 3: “dentro da faculdade se faz esse tipo de } \\
\text { treinamento com os funcionários e orientação tanto aos } \\
\text { docentes, discentes e em campanhas até de coleta de } \\
\text { resíduos". }\end{array}$ \\
\hline $\begin{array}{l}\text { Treinamento e sensibilização } \\
\text { dos alunos em relação à } \\
\text { sustentabilidade }\end{array}$ & $\begin{array}{l}\text { INST 1: "Alguns cursos realizam”. } \\
\text { INST 2: “os alunos já entram em um formato de agentes } \\
\text { replicadores". } \\
\text { INST 3: “...essa equipe fazia a sensibilização nas salas de } \\
\text { aula ...". }\end{array}$ \\
\hline
\end{tabular}


Quadro 4 - Continuação

\begin{tabular}{|c|c|}
\hline \multicolumn{2}{|r|}{ Gestão Ambiental } \\
\hline Principais práticas & Evidências \\
\hline $\begin{array}{l}\quad \text { Inclui a sustentabilidade } \\
\text { ambiental nos currículos de } \\
\text { graduação e/ou pós-graduação }\end{array}$ & $\begin{array}{l}\text { INST 1: “... ainda não há uma consciência de que a } \\
\text { sustentabilidade esteja envolvida em cada curso, em cada } \\
\text { área". } \\
\text { INST 2: “... o Direito Ambiental é uma das áreas que } \\
\text { tem demandado bastante interesse dos alunos e a } \\
\text { sustentabilidade, ela é tocada em disciplinas optativas e } \\
\text { em disciplinas da grade hoje”. } \\
\text { INST 3: “... todos eles tem a disciplina que trata a questão } \\
\text { do meio ambiente". }\end{array}$ \\
\hline $\begin{array}{l}\text { Controle do uso da energia/ } \\
\text { eficiência energética }\end{array}$ & $\begin{array}{l}\text { INST 1: “Tem vários projetos"; “Hoje, nós estamos até } \\
\text { substituindo as lâmpadas que ficam ligadas à noite por } \\
\text { modelos mais apropriados". } \\
\text { INST 2: “Não existe controle. Na verdade existe mais uma } \\
\text { promoção ...". } \\
\text { INST 3: “Existe esse grupo que faz esse trabalho nas salas } \\
\text { com os professores de conscientização do consumo". }\end{array}$ \\
\hline $\begin{array}{l}\text { Programa de reciclagem e/ou } \\
\text { gestão de resíduos }\end{array}$ & $\begin{array}{l}\text { INST 1: “Nós temos a coleta seletiva onde os resíduos são } \\
\text { doados para instituições de catadores". } \\
\text { INST 2: "Nós só temos o incentivo da separação do lixo } \\
\text { que é em todas as áreas de lazer da instituição". } \\
\text { INST 3: "tem um convênio com um grupo de catadores } \\
\text { que vem dentro da instituição pra buscar tudo aquilo que } \\
\text { é reciclável". }\end{array}$ \\
\hline $\begin{array}{l}\quad \text { Analisa critérios de gestão } \\
\text { ambiental dos seus fornecedores } \\
\text { de materiais de consumo }\end{array}$ & $\begin{array}{l}\text { INST 1: "Já temos ferramentas neste sentido. Alguns } \\
\text { locais já fazem isto". } \\
\text { INST 2: "quando se faz uma escolha, critérios como este } \\
\text { são levados em consideração através da controladoria”. } \\
\text { INST 3: “... se tem esse cuidado por causa dessa orientação } \\
\text { da SIPA dos trabalhos". }\end{array}$ \\
\hline
\end{tabular}

ambiental. Com relação à sensibilização dos alunos, a instituição informou que foi oferecido cursos e fóruns, porém, o retorno foi baixo. Constatou-se que a INST2, através da comunicação interna, realiza oficinas, palestras e seminários para o aprimoramento pessoal e profissional dos funcionários. $\mathrm{Na}$ INST3, verificou-se que há treinamento e orientação para os docentes e discentes.

Para a inclusão da sustentabilidade ambiental nos currículos de graduação e pós-graduação a INST1 informa que houve petições via comissão ambiental para que os cursos insiram a questão sustentável em seus currículos, porém, ainda não há a consciência de que a sustentabilidade esteja 
incluída em cada curso. A INST2, através do seu curso de graduação, oferta a disciplina de Direito Ambiental, uma área considerada promissora, enquanto que na pós-graduação ainda está em fase de planejamento. Já na INST3, o responsável pelas informações relatou que em todos os cursos de graduação há a disciplina que trata a questão do meio ambiente.

No que diz respeito à eficiência energética, nenhuma instituição controla o seu uso de energia, contudo, a INST1 promoveu algumas ações isoladas para diminuir o consumo de energia elétrica além de possuir vários projetos como, por exemplo, a utilização de energia fotovoltaica em um de seus espaços. Nas demais instituições, ocorrem ações pontuais que ficam restritas à conscientizações nas salas de aula. Lacy et al. (2010), porém, diz que a sustentabilidade deve estar totalmente integrada às operações e as estratégias de uma organização, não devendo ser vista de forma individual, ocorrendo em apenas alguns setores ou processos.

Observou-se, também, que as três instituições analisadas não possuem programas de gestão de resíduos, apenas realizam a coleta seletiva de lixo e, ainda, a INST1 e a INST3 possuem convênio com associações de catadores para que seja realizada a reciclagem, corroborando Barbieri (2004), onde relata que na maioria dos programas de cursos superiores a educação ambiental limita-se à realização de atividades isoladas no dia do meio ambiente ou aos programas de coleta seletiva de lixo nas dependências da instituição.

Quando perguntado se a instituição analisa critérios de gestão ambiental dos seus fornecedores de materiais de consumo, as entrevistadas informaram que há esta avaliação no processo de compra. A INST1 afirma que possui ferramentas para este tipo de avaliação em alguns setores. Já a INST2 informa que o setor de controladoria tem como obrigação funcional a análise do perfil dos fornecedores e parceiros. Por fim, a INST3 diz que há esta averiguação para a aquisição de materiais junto aos fornecedores, como exemplo, a compra de condicionadores de ar que agridem menos o meio ambiente.

\section{CONSIDERAÇÕES FINAIS}

O presente estudo teve como objetivo identificar as práticas de gestão ambiental adotadas pelas Instituições de Ensino Superior (IES) presenciais da cidade de Santa Maria/RS. A partir da análise de três instituições, caracterizou-se os resultados em três categorias de análise: estrutura física, legislação normativa e gestão ambiental.

Com relação a estrutura física, as evidências indicam que, embora as instituições demonstraram-se preocupadas em seguir padrões sustentáveis em suas construções e reformas de modo a reduzir as agressões ao meio ambiente, essas ações ainda são pouco praticadas, devido aos custos envolvidos e, portanto, ficam restritas a ações pontuais. Ressalta-se que apenas uma instituição possui espaços verdes, porém, a promoção da biodiversidade dos ecossistemas é relativo, pois o cultivo da vegetação arbustiva realizado pela instituição não representa o bioma original.

Quanto à legislação, observou-se que nenhuma das instituições respondentes possui algum padrão de certificação ambiental, sendo que apenas uma delas afirma ser uma meta futura da organização. Esta é a realidade da maioria das instituições de ensino superior do país e pode ser explicado pela falta de consciência por parte dos gestores ou pela necessidade de criação de equipes focadas à gestão ambiental para criar condições para a certificação, o que gera um aumento nas despesas da instituição.

$\mathrm{Na}$ análise sobre a gestão ambiental, evidenciou-se que as instituições pesquisadas não têm, como cultura, a realização de auditoria ambiental formalizada e específica da organização, no entanto, realizam treinamento e sensibilização dos alunos e funcionários em relação a sustentabilidade, oferecendo periodicamente cursos, oficinas, palestras e seminários. Outro aspecto relevante é que há a inclusão da sustentabilidade nos currículos de graduação e pós-graduação nas instituições analisadas, porém, devido ao elevado número de cursos que uma das instituições oferece, ainda não foi possível a inclusão desta temática em todos os cursos da organização.

Apesar de todas elas realizarem a coleta seletiva de lixo, nenhuma instituição possui programa de gestão de resíduos, o qual visa não só o recolhimento e destinação dos detritos mas, também, o controle da produção para a redução destes resíduos. Na promoção do controle de energia, verificou-se que as instituições apenas realizam procedimentos de fácil aplicação como, por exemplo, a troca 
de equipamentos por outros mais eficientes a fim de obter redução no consumo de energia elétrica, ou ações restritas à conscientização de alunos e funcionários.

Por fim, o estudo revelou que as práticas de gestão ambiental adotadas pelas instituições analisadas são incipientes e que estas ações caracterizam-se como isoladas por serem implementadas apenas em alguns setores da organização. Percebeu-se, também, a dificuldade de implementação de outras práticas pela questão financeira, quando gestores deparam-se em elevados custos de execução, tendo em vista que os recursos são, muitas vezes, limitados. Apesar disso, as instituições analisadas mostraram-se preocupadas com a questão ambiental e procuram, em muitos casos, a conscientização dos seus alunos e funcionários.

Como sugestões para trabalhos futuros, propõem-se a identificação das práticas de gestão ambiental possuindo variáveis além das diretrizes e regulamentações, aplicadas há uma população mais representativa de outras regiões.

\section{REFERÊNCIAS}

ALIGLERI, L.; ALIGLERI, L. A.; KRUGLIANSKAS, I. Gestão socioambiental: responsabilidade e sustentabilidade do negócio. São Paulo: Atlas, 2009.

AMARAL, S. P.; LA ROVERE, E. L. Indicators to evaluate environmental, social and economic sustainability: a proposal for the Brazilian oil industry. Oil \& Gas Journal. Tulsa,May, v. 101, p.30, 2003.

ASSOCIAÇÃO BRASILEIRA DE NORMAS TÉCNICAS. NBR ISO 14001: diretrizes gerais sobre princípios, sistemas e técnicas de apoio. Rio de Janeiro: ABNT, 1996.

ASSOCIAÇÃO BRASIELIRA DE NORMAS TÉCNICAS. NBR ISSO 14001: sistema de gestão ambiental: requisitos com orientação para uso. Rio de Janeiro: ABNT, 2004.

BARBIERI, J. C. Educação ambiental e a gestão ambiental em cursos de graduação em administração: objetivos, desafios e propostas. Revista de Administração Pública, 38(6), p. 919-946, 2004.

BARBIERI, J. C. Gestão ambiental empresarial: conceitos, modelos e instrumentos. 2. ed. São Paulo: Saraiva, 2007.

BRASIL. Ministério da Educação e do Desporto. A implantação da educação ambiental no Brasil. Brasília, 1998. 166 p.2004.

CARETO, H.; VENDEIRINHO, R. Sistemas de gestão ambiental em universidades: caso do Instituto Superior Técnico de Portugal. Relatório Final de Curso, Instituto Superior Técnico de Portugal, 2003.

CMMAD, Comissão Mundial sobre Meio Ambiente e Desenvolvimento. Nosso Futuro Comum. 2 ed. Rio de Janeiro: Editora da Fundação Getúlio Vargas, 1991.

COUTO, A., MATOS, F., CARVALHO, P. G., e ALVES, M., 2004b. "Universidade da Beira Interior e sua relação com a região: fundamentos para uma gestão estratégica. ANAIS DA REDE LFA PL n GIES, LappLane, S. Paulo: 99-193, 2004.

DELGADO, C. C. J.; VÉLEZ, C. Q. Sistema de gestión ambiental universitária: caso Politécnico Gran Co-lombiano.2005.

DIAS, R. Gestão ambiental: responsabilidade social e sustentabilidade. 2 ed. São Paulo: Atlas: 2011.

EISENHARDT, K. M. Building theories from case study research. Academy of Management Review. V. 14, n. 4, p. 532-550, 1989. 
ELKINGTON, J. Cannibals with Forks: the triple bottom line of 21st century business. Canada: NSP, 1998.

ENGELMAN; R., GUISSO; R., FRACASSO, E. M. Ações de gestão ambiental nas Instituições de Ensino Superior: o que tem sido feito. RGSA - Revista de Gestão Social e Ambiental, v. 3, n. 1, 2009.

FARIAS, J. S.; TEIXEIRA, R. M. A pequena e micro empresa e o meio ambiente: a percepção dos empresários com relação aos impactos ambientais. RevistaOrganizações \& Sociedade. v. 13, n. 36, p. 1-20, Jan./Mar. 2006.

GIL, A. C. Métodos e técnicas de pesquisa social. São Paulo: Atlas, 2007.

GUIMARÃES, S. S. M.; TOMAZELLO, M. G. C. A formação universitária para o ambiente: educação para a sustentabilidade, 2011.

JACOBI, P. Educação ambiental, cidadania e sustentabilidade. Cadernos de Pesquisa. n.118, p. 189-205, Mar. 2003.

LACY, P., COOPER, T., HAYWARD, R., NEUBERGER, L. A New Era of Sustainability. UN Global Compact-Accenture CEO Study, Accenture. 2010.

MAYOR, F. Preparar um futuro viável: ensino superior e desenvolvimento sustentável. In: Conferência mundial sobre o ensino superior. Tendências de educação superior para o século XXI. Anais. Paris: 1998.

MORAES, R. Análise de conteúdo. Revista Educação, v. 22, n. 37, p.7-32, Porto Alegre, 1999.

NASCIMENTO, L. F.; LEMOS, A. D. C.; MELLO, M. C. A. Gestão socioambiental estratégica. Porto Alegre: Bookman, 2008.

PLACET, M., ANDERSON, R., FOWLER, K., M. Strategies for Sustainability. Research Tecnology Management, v. 48, n. 5, p. 32-41, 2005.

RIBEIRO, M. S. L.; PROFETA, A. C. N. A. Programas de educação ambiental no ensino infantil em Palmeiras de Goiás: novos paradigmas para uma sociedade responsável. Revista Eletrônica do Mestrado em Educação Ambiental. V. 13, Jul./Dez. 2004.

SACHS, I. Estratégias de transição para o século XXI: desenvolvimento e meio ambiente. São Paulo: Nobel, 1993.

SILVA, L. M. T. da; SILVA, M. P da; ENDERS, W. T. Gestão ambiental e desempenho organizacional: um estudo de suas relações no setor hoteleiro. In: ENCONTRO ANUAL DA ASSOCIAÇÃO NACIONAL DOS CURSOS DE PÓS-GRADUAÇÃO EM ADMINISTRAÇÃO, 30., 2006, Salvador. Anais eletrônicos... Salvador: ANPAD, 2006.

SILVA, V. B. da; CRISPIM, J. de Q. Um breve relato sobre a questão ambiental. Revista GEOMAE - Geografia, Meio Ambiente e Ensino, v. 02, nº 01, 2011.

TAUCHEN, J.; BRANDLI, L. A gestão ambiental em Instituições de Ensino Superior: modelo para implantação em Campus Universitário. Gestão e Produção, v.13, n.3, 2006.

YIN, R. K. Case study research: design and methods. Reviewed. California: Sage Publications, 1990.

YIN, R. K. Estudo de caso: planejamento e métodos. 5 ed. Porto Alegre: Bookman, 2011.

WEENEN, H. Towards a vision of a sustainable university. International Journal of Sustainability in Higher Education, v. 01, n 1, pp. 20-34, 2000. 